\title{
In Vitro Scolicidal Effects of Sideritis perfoliata Aerial Part Extract against the Protoscoleces of Echinococcus granulosus
}

\author{
TUNCAY Çelik ${ }^{1}$, Muhittin Önderci ${ }^{2}$, Mustafa Pehlivan ${ }^{2}$, and Önder Yumrutaş ${ }^{3}$ \\ ${ }^{1}$ Adiyaman Universitesi Tip Fakultesi \\ ${ }^{2}$ Affiliation not available \\ ${ }^{3}$ Adiyaman University
}

January 17, 2021

\begin{abstract}
Background: Cystic echinococcosis (CE) is commonly located in the liver and lungs of affected hosts. Surgical management is one of the best choices for the treatment of hydatidosis and using effective scolicidal agents during hydatid surgery is essential to prevent secondary infection. The present study was designed to investigate the in vitro scolicidal activity of methanol extract of Sideritis perfoliata against the protoscoleces of hydatid cysts. Methods: The protoscoleces were collected from slaughtered livestock in Adiyaman and the effect of three concentrations of the aerial part extract of S. perfoliata $(0.1 \mathrm{mg} / \mathrm{ml}, 0.2 \mathrm{mg} / \mathrm{ml}$, and $0.4 \mathrm{mg} / \mathrm{ml}$ ) was assessed over three different exposure periods. All tests were carried in dublicate. Finally, the mortality of protoscoleces was assessed by the eosin exclusion test ( $0.1 \%$ eosin staining). Methanol extract of S. perfoliata was assessed by Liquid Chromatography-Mass Spectrometry/Mass Spectrometry (LC-MS/MS). Results: The results showed that the scolicidal effect of this extract at exposure periods of 10,20 , and $30 \mathrm{~min}$ was $29.6,32.5$, and $43.6 \%$ at concentrations of $0.1 \mathrm{mg} / \mathrm{ml}, 37.8,50$, and $58.1 \%$ at concentration of $0.2 \mathrm{mg} / \mathrm{ml}$ and finally $57.9,71.8$, and $79.1 \%$ at concentration of $0.4 \mathrm{mg} / \mathrm{ml}$, respectively; indicating that the extract requiring a further time to display a potent protoscolicidal effects. Some phenolic acids such as fumaric acid $(260,13 \mathrm{mg} / \mathrm{L})$, syringic acid $(27,92 \mathrm{mg} / \mathrm{L})$ and caffeic acid $(26,84 \mathrm{mg} / \mathrm{L})$ and a flavonoid, luteolin $(11,23 \mathrm{mg} / \mathrm{L})$ were detected in high concentrations. Conclusions: The present study has demonstrated that the methanol extract of S. perfoliata has high scolicidal power in vitro, although the low concentration of plant extract may provide a base for future treatment of hydatid cysts. However, more research on the in vivo efficacy of S. perfoliata extract and its potential side effects is recommended.
\end{abstract}

\section{Hosted file}

\selectlanguage\{ngerman\}Çelik T. et al 07.12.2020.pdf available at https://authorea.com/ users/389895/articles/504417-in-vitro-scolicidal-effects-of-sideritis-perfoliata-aerialpart-extract-against-the-protoscoleces-of-echinococcus-granulosus 